\title{
ASSESSMENT OF STEREOLITHOGRAPHIC MODELING TECHNOLOGY VERSUS CONVENTIONAL RECONSTRUCTIVE PLATE IN PATIENTS WITH MANDIBULAR DISCONTINUITY DEFECTS
}

\author{
Amany Khalifa El-Sayed* and Ahmed Mohammed Salah**
}

\begin{abstract}
Introduction : One of the goals of mandibular reconstruction after tumor resection is to return to premorbid form and function. Both stereolithography (SLG) and a conventional reconstructive (CR) plates with bone replacement are a valuable for reconstruction following resection of tumors.

Purpose: The aim of this study was to compare the outcome of (SLG) modeling technology versus (CR) plate in cases of tumor resection.

Materials and Methods: Patients eligible for inclusion in this study had unilateral mandibular discontinuity defects. Patients were randomly divided into 2 groups. Each group comprised 10 patients. In group I (study group), (SLG) modeling technology plates were used, while group II (control group) used (CR) plates. The lesions were resected, and their sites were reconstructed using last mentioned plates, with autogenous bone graft in a second stage. The need for intraoperative plate readjustment, plate placement time and operation time were reviewed.
\end{abstract}

Results: Twenty patients were enrolled in this study. In group I, plates were placed without intraoperative handling. All plates in group II required readjustment. Average operating times were $3.200 \pm 0.258$ hours in group I and $4.325 \pm 0.290$ hours in group II $(P=.000)$. Mean times for plate placement were $22.900 \pm 2.234$ minutes and $32.900 \pm 2.234$ in groups I and II, respectively. The difference resulted in an average time gain of 10 minutes.

Conclusion: (SLG) modeling technology is superior in reflecting the bone anatomy than (CR) plate, thus the plate prebending using SLG, eliminating intraoperative plate readjustment and providing better plate adaptation with better contour. It decreases operating time.

* Lecturer of Oral and Maxillofacial Surgery, Faculty of Oral and Dental Medicine, El Nahda University

** Fellow of Oral and Maxillofacial Surgery, Ahmed Maher Teaching Hospital. 


\section{INTRODUCTION}

Extensive resection of tumor tissue often creates major bone and soft tissue defects, which have functional and esthetic consequences. It also leads to retrusion of the lower third of the face and severe ptosis of the lower lip. Resection involving the body of the mandible leads to facial asymmetry with sinking of the affected side ${ }^{1,2}$ So one of the goals of mandibular reconstruction after tumor resection is a return to premorbid form and function. The typical reconstruction includes a titanium bone plate and bone replacement with a graft or vascularized flap. (SLG), which began to be used in the $1980 \mathrm{~s},{ }^{3,4,5}$ is a valuable adjunct to traditional methods of treatment planning for reconstruction following resection of tumors, developmental abnormalities, or trauma reconstruction ${ }^{6}$.

(SLG) uses computer technology and medical image processing techniques to generate a complex plastic 3-dimensional (3D) model from computed tomography (CT) scans. When (SLG) technology is incorporated into the reconstruction procedure, the work up and operative phases can be improved and treatment can be enhanced. ${ }^{5}$

This article compares the outcome of (SLG) modeling technology versus (CR) plates after extraoral resection of mandibular ameloblastoma.

\section{MATERIALS AND METHODS}

\section{Study design and sample}

To address the purpose of the present study, the authors designed and performed a randomized control trial comparing 2 groups, one of them used to format 3dimentional (3D) virtual models and the other had (CR) plates. Twenty patients who attended Oral and Maxillofacial Surgery department, Ahmed Maher teaching Hospital (Cairo, Egypt), from March 2013 to March 2017, with chief complaint of mandibular swelling. All patients were informed about the research and they provided written informed consent to participate in the study.

\section{Data collection method}

The demographic and clinical data were abstracted from the patients' charts: age, gender, lesion duration and the side of the mandibular defect.

\section{Study variables}

\section{Primary Predictor Variable}

Twenty patients were randomly allocated; 10 for group I and other 10 for group II. During the randomization process and before starting the study, each patient was given a number $(1,2,3$, etc.) according to their attendance date at the clinic. Then, they were categorized by even versus odd number.

\section{Virtual Planning Technique}

Preoperative CT scan was requested for both groups with a slice thickness of $0.5 \mathrm{~mm}$ as Digital Imaging and Communication in Medicine (DICOM) in the form of axial, coronal and sagittal sections. In group I, DICOM files were transformed into 3D bony reconstruction virtual model. The area of interest was selected on this model, the tumor removed virtually by using the advantage of $3 \mathrm{D}$ software technology, and to get the optimum mandibular contour, a mirror image of the unaffected side was done with overlapping to the area of resection. The final model was printed using the technology of 3D printer. Then, the stereolithographic models were fabricated and prototyped.The models were used for preoperative bending of the conventional $2.7 \mathrm{~mm}$ reconstruction plates to bridge the prospective mandibular defects. The finished plates were subjected to autoclave sterilization before surgery ${ }^{7}$ (Figure (1)).

\section{Surgical management}

\section{Preoperative Preparation:}

Under local anesthesia, incisional biopsy specimens were taken for histopathologic analysis, and the appropriate treatment plan was chosen according to the histopathologic report where it revealed amelobalstoma for all cases. Arch bars 

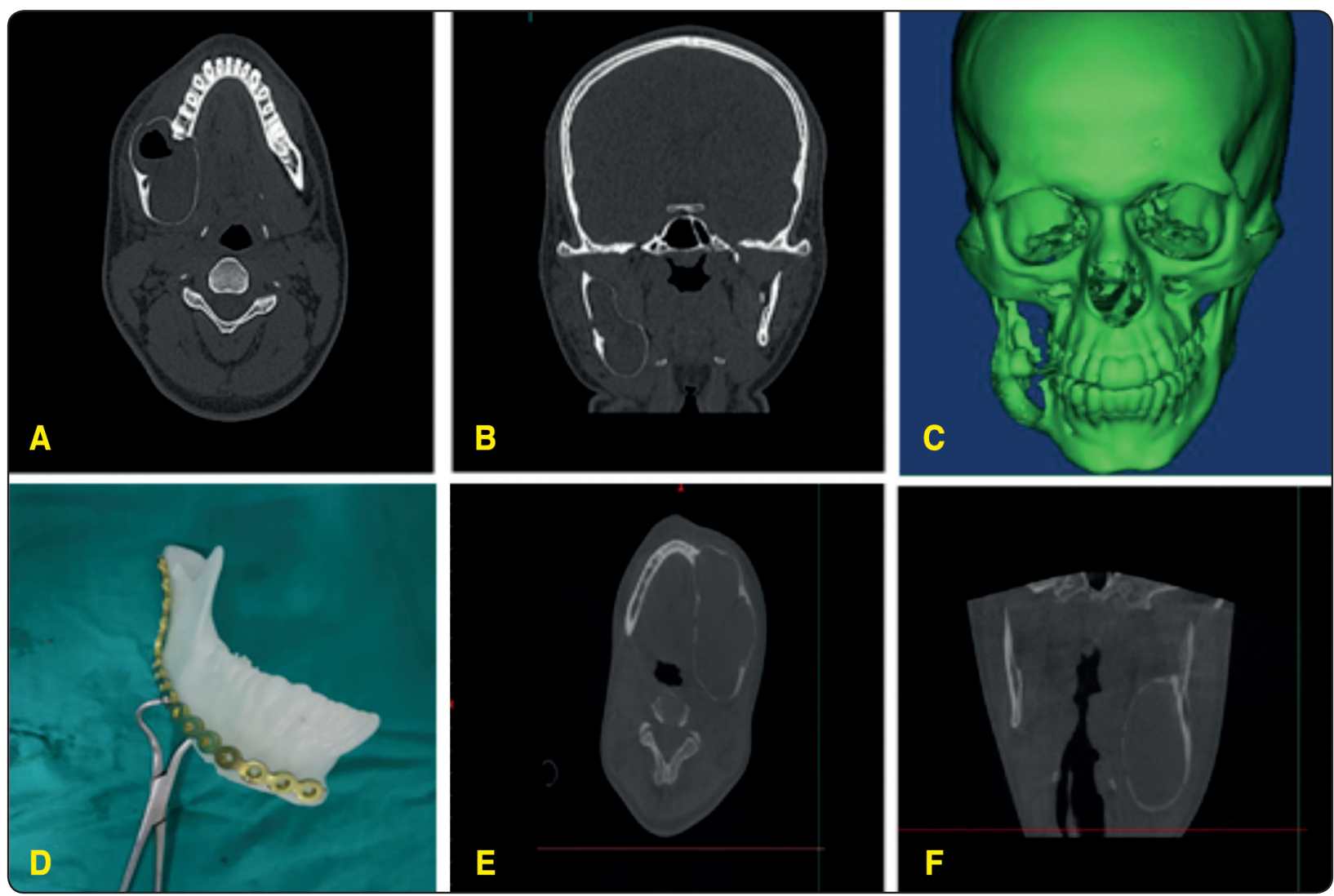

Fig. (1), Group (I), (A) C T radiograph showing, axial view, mediolateral extention of the right sided ameloblastoma (B) C T radiograph showing coronal view, superioinferior extention of the lesion. (C) $\mathrm{C} T$ radiograph showing three dimensional view of the lesion. (D) photograph showing preoperative bending of (SLG) reconslruction plate. Group (II) (E), C T radiograph showing, axial view, mediolateral extention of the left sided ameloblastoma. $(\mathrm{F}) \mathrm{C} \mathrm{T}$ radiograph showing coronal view, superioinferior extention of the lesion.

were applied on the upper and lower jaws for all patients 1 day before surgery to minimize possible confounding factors.

\section{Surgical Procedures}

The operations were performed under general anesthesia through extraoral approaches. Care was taken during tumor dissection to preserve the oral mucosa. The tumors were resected without condylar disarticulation according to the planned osteotomy lines and submitted for histopathologic examination. Operation time was measured in hours starting from flap reflection and tumor exposure to end of suturing, plate placement time was recorded in minutes and blood loss was measured in milliliters. Then, for all patients, intermaxillary wiring was performed to maintain occlusion on the unaffected side. In group I The virtually planned pre-bent (SLG) reconstruction plates were positioned and screwed into the proximal and distal segments by 4 titanium bicortical screws at each side, while in group II prior to resection, a malleable template was adapted along the buccal surface close to the inferior border of the mandible. The reconstruction plate was then bent to conform to the shape of the template. The final adjustments were made directly on the mandible. Good adaptation to the buccal surface at both ends of the plate must be obtained. The plate was attached to the mandible with four (2.7) $\mathrm{mm}$ bicortical screws placed through pretaped drill holes at each end. The plate was then removed and following resection was replaced, giving an exact realignment of the mandibular segment with precise preservation of the preoperative occlusion ${ }^{8}$ (Figure (2)). 


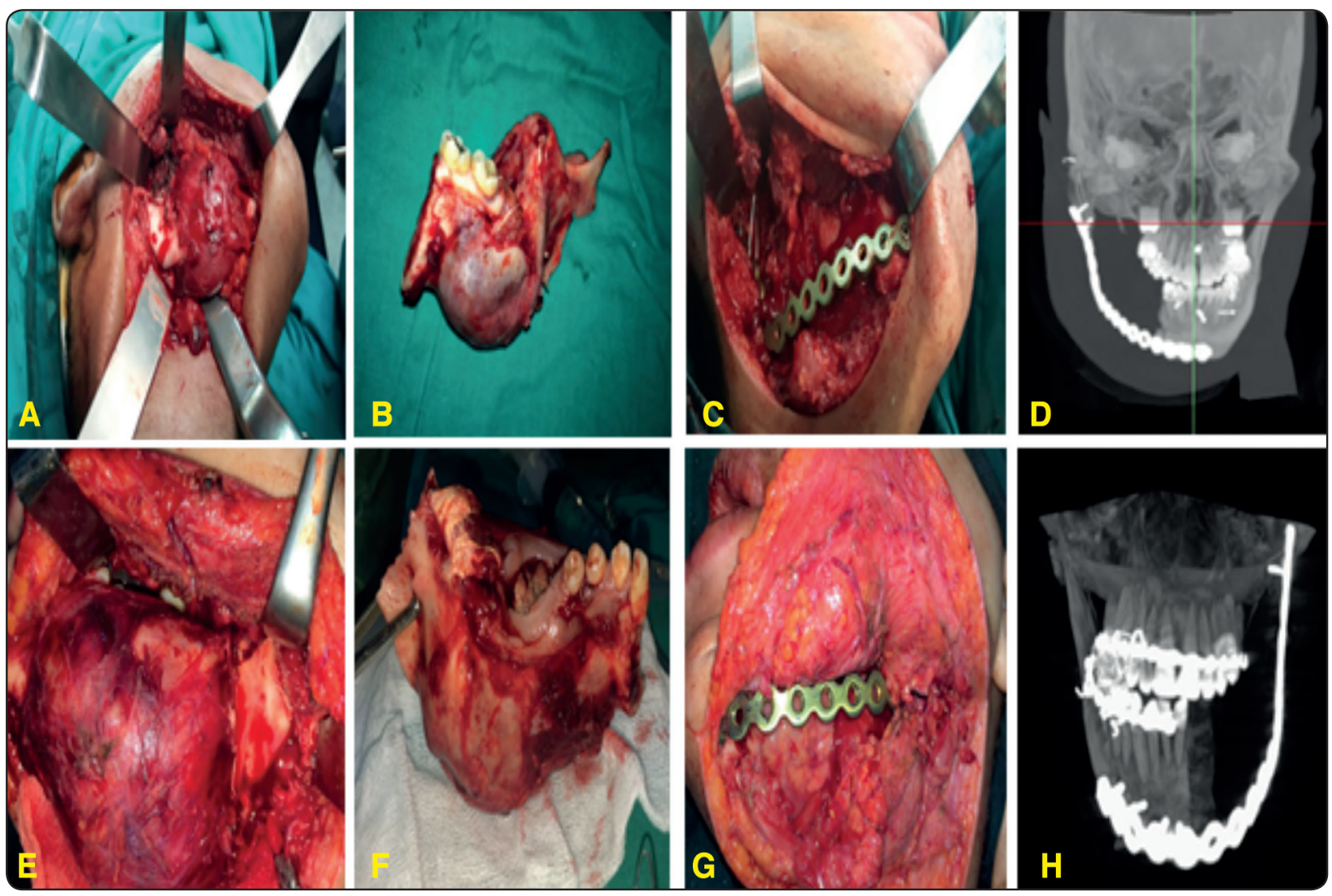

Fig. (2), Group (I), (A) Photograph showing, supraperiosteal dissection \& exposure of right sided ameloblastoma (B) Resected lesion (extended from lower night first molar to subcondylar area) with safety margin. (C) Photograph showing adaptation of (SLG) reconstruction plate. (D) Postoperative three dimensional C T radiograph showing plate fixation with bicorticaJ screws. (E), Group (II) Photograph showing, supraperiosteal dissection \& exposure of left sided ameloblastoma. (F) Resected lesion (extended from lower left lateral incisor to subcondylar area) with safety margin. (G) Photograph showing intraoperative adaptation of free hand bent $(\mathrm{C} R)$ plate. $(\mathrm{H})$ Postoperative three dimensional $\mathrm{C}$ T radiograph showing plate fixation with bicortical screws.

\section{Postoperative Follow-Up}

Follow up was done for all patients to detect wound dehiscence, presence of soft tissue infection, plate exposure, occlusion on the unaffected side, and facial contours.

\section{Data analysis}

The variables were determined, compared, and statistically analyzed. Descriptive statistics were analyzed

With Pearson $\mathrm{x}^{2}$ tests, and means and proportions were compared with independent-sample $t$ test and $\mathrm{x}^{2}$ test; $\mathrm{P}$ values less than .05 were considered statistically significant.

\section{RESULTS}

The study included 20 patients with unilateral mandibular bridging defects as a result of resection of ameloblastoma. They were divided randomly and equally into 2 groups. The defects were treated by immediate mandibular reconstruction with preoperative planning. In group I, (SLG) modeling technology plate was used. while in group II, (CR) plate was applied. All patients were operated on by the same surgeons working as a team. Preoperative data were collected. Patients' mean age was $36.400 \pm 7.397$ years in group I and $35.900 \pm 7.156$ years in group II, with no significant difference between both groups $(\mathrm{P}=.880)$. 
The gender distribution showed women comprised $40 \%$ of group I and $60 \%$ of group II. Average lesion duration was $6.300 \pm 1.703$ months in group $\mathrm{I}$ and 5.400 \pm 2.119 months in group II $(\mathrm{P}=.6309)$ (Table1). Histopathologic results had documented ameloblastoma in all cases in both groups. After surgical exposure, mandibular resection was performed in all cases following the preoperative planned osteotomy sites. All reconstruction plates were placed without difficulty. In group I, no readjustment was needed, while in group II, all the plates required minimal readjustment. Operating time ranged from 3.00 to 3.75 hours (average, $3.200 \pm 0.258$ hours) in group I and from 4.00 to 4.75 hours (average, $4.325 \pm 0.290$ hours) in group II ; approximately 1 hour was increased in group II, which was highly significant $(\mathrm{P}=.000)$. In addition, the mean time for plate placement in group I; which did not need any readjustment was only $22.900 \pm 2.234$ minutes (range, 20 to 25 minutes.
In group II was $32.900 \pm 2.234$ minutes (range, 30 to 35 minutes) because all conventional plates need readjustment to be adapted to the residual bone surfaces. This difference resulted in an average time gain of 10 minutes from plate placement in favor for group I. Furthermore, blood loss was 380 to $400 \mathrm{~mL}$ (average $388.000 \pm 6.325 \mathrm{~mL}$ ) in group I and 390 to $440 \mathrm{~mL}$ (average, $422.000 \pm 15.312 \mathrm{~mL}$ ) in group II $(\mathrm{P}=.000)($ Table 2$)$. All surgical sites showed uneventful wound healing and no postoperative soft tissue infection or plate exposure except for some edema. In addition, all patients in both groups displayed a proper facial contour during the entire follow up period. Three cases (1 patient in group I and 2 in group II) presented with occlusal discrepancies in the form of a posterior cross bite on the unaffected side. These patients responded to elastic traction for 15 days, their occlusion became stable and there was no functional impairment, so no need for a surgical revision.

TABLE (1) Distribution of patients' data between groups

\begin{tabular}{|l|c|c|c|}
\hline Characteristics & Group I & Group II & P Value \\
\hline Number of patients & 10 & 10 & .880 \\
\hline Age (year), mean & $36.400 \pm 7.397$ & $35.900 \pm 7.156$ & .371 \\
\hline Gender, $\%$ & & & \\
\hline Men & 60 & $60.05 *$ \\
\hline Women & 40 & $5.400 \pm 2.119$ & .309 \\
\hline Lesion Duration (month), mean & $6.300 \pm 1.703$ & & .653 \\
\hline Affected side, $\%$ & & & $>0.05 *$ \\
\hline Left & 50 & 60 & \\
\hline Right & 50 & & \\
\hline
\end{tabular}

* Non significant difference between both groups $(P>0.05)$ 
TABLE (2) Intraoperative records of both groups

\begin{tabular}{|l|c|c|c|}
\hline Characteristics, Mean & Group I & Group II & P Value \\
\hline Operating time (hour) & $3.200 \pm .258$ & $4.325 \pm .290$ & $.000<0.01^{*}$ \\
\hline Duration of plate placement (minutes) & $22.900 \pm 2.234$ & $32.900 \pm 2.234$ & $.000<0.01^{*}$ \\
\hline Amount of blood loss (milliliter)** & $388.0006 .325 \pm$ & $422.000 \pm 15.312$ & $.000<0.01^{*}$ \\
\hline
\end{tabular}

*Highly Significant difference between both groups $(P<0.01)$ in favor of group I.

**Blood loss was evaluated after subtracting irrigation from suction canisters and from sponge weight. This was performed by an anesthesiologist.

\section{DISCUSSION}

Operations for mandibular reconstruction have changed since the introduction of preoperative virtual planning. This technology helps surgeons better understand the steps of the reconstructive procedure and focus on achieving optimal shaping of the bony segments. ${ }^{9,10}$. Many investigators have reported that, when applying 3D models to clinical cases, better accuracy is obtained ${ }^{11,12}$. The plates should correspond with the mandibular shape in its 3 dimensions, not only to avoid any bending during the operative phase, but also to obtain an accurate contour. This is in agreement with other studies. ${ }^{5,13,14,15}$ Bending the plates during surgery is an important cause of (CR) plate fracture during function because of residual stress generation, which leads to subsequent fatigue loading. ${ }^{13-16}$. In group I, all plates did not require any readjustment in the operating theater, thus saving time and preserving the strength of the plate. In group II, The authors believe that, the wasted time of intra-operative plate bending was due to; first the plate was bent to conform to the shape of the template, then, the final adjustments were made directly on the mandible to conform to the normal mandibular contour. Good adaptation to the buccal surface at both ends of the plate must be obtained.
Finally, this result of group I is in agreement with some studies that have reported that (SLG) modeling technology plate is sufficiently accurate to be recommended for virtually planned pre-bent reconstruction plates and in disagreement with group II ${ }^{9,15,17}$. Many investigators also have reported that the accuracy of the 3D models depends mainly on the thickness of the CT scans, which should be as thin as possible $(0.5 \mathrm{~mm})$; the field of view also should have a resolution of 512 X 512 with the absence of tilting during image acquisition ${ }^{14,18}$. This could explain why the pre-bent plates in group I required no readjustment. Some investigators have reported that the (SLG) modeling technology plate provide other benefits, including decreased exposure to general anesthesia, decreased blood loss, and decreased wound exposure ${ }^{7}$. The results of the present study are in accordance with that study; the present results showed a substantial decrease in operating time, plate placement time, and the amount of blood loss in group I in which patients exhibited shorter time variable. By using (SLG) modeling technology plate, approximately 60 minutes was saved in the operating room and the calculated average time gain from plate placement was approximately 10 minutes. This is because (CR) plate in group II constituted a time-consuming factor from readjustment that resulted in a considerable 
increase in time variables with subsequent blood loss. The potential elimination of readjustment of the pre-bent plate not only decreases theater time but also ischemic time for the flap, which improves patient outcomes and lowers the risk of complications such as venous thrombo-embolism and postoperative infection and edema. This also has been suggested by other investigators 9,19 .

In conclusion, (SLG) modeling technology is superior in reflecting the bony anatomy thus producing more accurate facial contouring and obviating intraoperative readjustment of the plate. This technique provides a more precise adaptation with preservation of plate strength. It also shortens operating time. Thus, it can be considered a reliable method for precise mandibular reconstruction after tumor resection.

\section{ACKNOWLEDGMENTS}

The authors thank the oral and maxillofacial team of Ahmed Maher Hospital (Cairo, Egypt) with special thanks to Dr. Mohammed Galal Behiery, professor and consultant of the department of oral and maxillofacial surgery for his assistance and performance during the surgeries.

\section{REFERENCES}

1. Cuesta M, Ochandiano S, Caicoya S O, Riba F, Ruiz B D, Cuéllar C N and Vila C N: Oral rehabilitation with osseointegrated implants in oncological patients. J Oral Maxillofac Surg 67:2485, 2009

2- Cuellar C N, Caicoya S J, Sanz J J, Cuellar I N, Muela C M and Vila C N : Mandibular Reconstruction With Iliac Crest Free Flap, Nasolabial Flap, and Osseointegrated Implants. Journal of Oral and Maxillofac Surg 72, (6 ): 1226, 2014

3. Abe M, Tabuchi K, Goto M, and Uchino A: Model-based surgical planning and simulation of cranial base surgery. Neurol Med Chir (Tokyo) 38:746, 1998

4. Berry E, Brown JM, Connell M, Cravien CM ,Efford ND, Radjenovic A and Smith MA : Preliminary experience with medical applications of rapid prototyping by selective laser sintering. Med Eng Phys 19:90, 1997
5- Cunningham L, Madsen M J, and Peterson G: Stereolithographic modeling technology applied to tumor resection. $\mathrm{J}$ Oral Maxillofac Surg. 63:873, 2005

6. Powers DB, Edgin WA and Tabatchnick L: Stereolithography: A historical review and indications for use in the management of trauma. J Craniomaxillofac Trauma 4:16, 1998

7- Khalifa GH, Abd El Moniem NA, Elsayed SA, MD,z and Qadry Y: Segmental Mirroring: Does It Eliminate the Need for Intraoperative Readjustment of the Virtually Pre-Bent Reconstruction Plates and Is It Economically Valuable? Journal of Oral and Maxillofac Surg. 74 ( 3 ): 621, 2015

8- Tayapongsak P, Morales M J and Marx RE: Preresection application of reconstruction plates for temporary mandibular reconstruction.Journal of Oral and Maxillofac Surg. 50 (3): 307,1992

9. Gil RS, Roig AM, Obispo CA, Morla A, Pagès CM and Perez JL: Surgical planning and microvascular reconstruction of the mandible with a fibular flap using computer-aided design, rapid prototype modelling, and precontoured titanium reconstruction plates: A prospective study. Br J Oral Maxillofac Surg 53:49, 2015

10. Roser SM, Ramachandra S, Blair H and Grist W, Carlson GW, Christensen AM, Weimer KA and Steed MB : The accuracy of virtual surgical planning in free fibula mandibular reconstruction: Comparison of planned and final results. J Oral Maxillofac Surg 68: 2824, 2010

11. Choi JY, Choi JH, Kim NK and Kim Y, Lee JK, Kim MK, Lee JH and Kim MJ : Analysis of errors in medical rapid prototyping models. Int $\mathrm{J}$ Oral Maxillofac Surg $31: 23,2002$

12. Schramm A, Suarez-Cunqueiro MM, Barth El, Essig H , Bormann KH , Kokemueller H , Rücke M and Gellrich $\mathrm{N} \mathrm{C}$ : Computer-assisted navigation in craniomaxillofacial tumors. J Craniofac Surg 19:1067, 2008

13- Yu y, ZhangWB, Wang Y, Liu XJ, Guo CB, and Xin Peng : A Revised Approach for Mandibular Reconstruction With the Vascularized Iliac Crest Flap Using Virtual Surgical Planning and Surgical Navigation . J Oral Maxillofac Surg $74: 1285,2016$

14. Yamada H, Ishihama K, Yasuda K, Hasumi-Nakayama Y, Okayama M, Yamada T and Furusawa K : Precontoured mandibular plate with three-dimensional model significantly shortened the mandibular reconstruction time. Asian J Oral Maxillofac Surg 22: 198, 2010. 
15 Cohen A, Laviv A, Berman P, Nashef R and Abu-Tair $\mathrm{J}$ : Mandibular reconstruction using stereolithographic 3-dimensional printing modeling technology. Oral Surg Oral Med Oral Pathol Oral Radiol Endod 108: 661, 2009.

16- Martola M, Lindqvist C, Hänninen $\mathrm{H}$ and Al-Sukhun $\mathrm{J}$ : Fracture of titanium plates used for mandibular reconstruction following ablative tumor surgery. J Biomed Mater Res Part B Appl Biomater 80: 345, 2007.

17. Lee JW, Fang JJ, Chang LR, andYu CK : Mandibular defect reconstruction with the help of mirror imaging coupled with laser stereolithographic modeling technique. J Formos Med Assoc 106:244, 2007

18- Sannomiya EK, Silva JV, Brito AA, Saez DM, Angelieri F and Dalben Gda S.: Surgical planning for resection of an ameloblastoma and reconstruction of the mandible using a selective laser sintering 3D biomodel. Oral Surg Oral Med Oral Pathol Oral Radiol Endod 106:e36, 2008

19. Zweifel DF, Simon C, Hoarau R, Pasche P and Broome M: Are virtual planning and guided surgery for head and neck reconstruction economically viable? J Oral Maxillofac Surg 73:170, 2015 